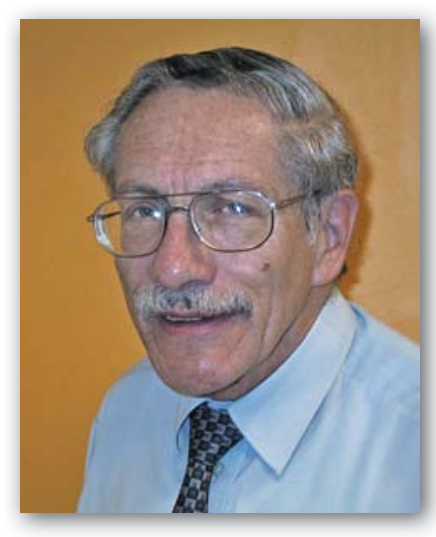

\title{
Prof Solomon Elias Levin (02 April I 929 - 12 July 2020)
}

It was with deep sadness that I learned of the passing of Prof Solly Levin a mere I I days after his wife Cynthia had also passed away.

Prof, as he was fondly referred to, was a legend in his time, recognised internationally in the field of Paediatric Cardiology and Paediatrics at Wits University.

He was a giant of a man, a gentleman and a gentle man who influenced countless students, registrars and fellows, over a career which spanned close to 70 years. His reputation was farreaching, and he made many close friends with most of the top Paediatric Cardiologists around the world. They all knew Solly well and referred to him with much admiration and respect.

He was officially acknowledged as the grandfather of Paediatric Cardiology in South Africa, a man who was willing to train, teach and mentor numerous junior doctors in this field over many years. Generations of students, registrars, fellows and colleagues are indebted to him as they clung to the pearls of wisdom, he willingly imparted, simplifying and bringing to life this fascinating growing, new field in cardiology.

He was born in Johannesburg on 2 April 1929. After schooling at Boksburg High School, he matriculated at the young age of 15 years with a first-class past. Medicine was a calling for him, and he qualified as a doctor at the University of the Witwatersrand in November 1950 at the age of 20 years. However, he had to wait another 6 months until he turned 21 before being allowed to graduate.

While waiting to qualify, he joined the Department of Physiology at the Wits medical school before commencing his internship year which was spent at Baragwanath Hospital in Medicine, Surgery and Paediatrics.

From 1953 - 1956 he studied in England working in the Paediatric Department at Guy's and Hammersmith Hospitals, as well as in the Departments of Pathology and Infectious Diseases.

In 1957, Prof joined the Department of Paediatrics at the Witwatersrand University and completed his registrar time in 1960.

Taking his studies further, Prof went on to do a Diploma in Child Health (D.C.H.) in London in 1955, qualifying with an M.R.C.P. in 1956 and thereafter a F.R.C.P. in 1972 (at the Royal College of Physicians in Edinburgh). 
As a consultant he worked in the Paediatric Department at Baragwanath Hospital from 1960 and moved across to the Transvaal Memorial Hospital (TMH) for children in 1965, where he remained until 1978.

In 1968, he was awarded the Cecil John Adams Memorial Trust Travelling Fellowship which enabled him to spend a year at the Children's Memorial Hospital and North Western University, Chicago as a fellow in Department of Paediatric Cardiology.

From 1970 - 1978 he was appointed as a Principal Paediatrician in the Department of Paediatrics at the $\mathrm{TMH}$ and then at the Johannesburg Hospital from 1978 until 1992. In 1974, he was appointed an Associate Professor in the Department of Paediatrics and then in 1978, ad Hominem Professor of Paediatric Cardiology through the University of the Witwatersrand.

At the age of 64 years Prof went into private practice but maintained a more than active part-time academic presence at the Johannesburg Hospital until 1998, which spanned an illustrious academic career of 41 years.

Prof never really retired at all and he continued to teach students and registrars with the same enthusiasm right until the very end. He maintained an ongoing interest in academic medicine and continued to contribute and present at our regular journal club meetings.

He felt he was never too old to learn new things and was always excited to hear about new cases and the new technology, whenever he visited our practice. He continued to teach and lecture right to the very end and he was working on a publication just before he died.

Prof's contribution to the world of academia remains legendary and he published well over 120 articles in both local and overseas journals including seven chapters in books. In addition, he participated on the editorial board of the Paediatric Cardiology and Cardiology in the Young Journals.

He presented at numerous local and overseas congresses and had a long association with the South African Heart Association, the Paediatric Cardiac Society of South Africa, as well as the College of Medicine of South Africa, where he was a founder and a member of the Examination and Credentials Committee.

For years he maintained an active role as an examiner for the Diploma of Child Health (DCH) and the Fellowship in Paediatrics (FCP-Paeds) as well as an examiner for the Fellowship of Paediatric Cardiology (SA). 


\section{Prof Solomon Elias Levin}

He was honoured and received many awards during his career.

In 1995, the Paediatric Cardiac Society of South Africa acknowledged his contribution to the field of Paediatric Cardiology. In 1998 the Johannesburg branch of the South African Heart Association also acknowledged and recognised his service in the advancement of Paediatric Cardiology in South Africa.

The University conferred on him the title of Emeritus Prof of Paediatric Cardiology in 1998 and in 2002 he received in Exceptional Service Medal from the Wits Faculty of Health Sciences.

Despite all these accolades, he remained an extremely humble man and never flaunted any of his achievements. His lectures and tutorials were never missed by the students and he was the ultimate clinician emphasising the importance of listening to a mother and taking a good history, warning the students to never ignore a mother's recount of her baby's symptoms. The examination of the patient always took precedence over technology (chest $x$-ray, electrocardiogram and echocardiogram).

Here was a man who truly lived through the rapidly changing field of Paediatric Cardiology from its infancy days to what it has currently become. He witnessed the brave new operations being tried when cardiopulmonary bypass was being established and also personally met most of the pioneers in this field.

Prof lived through the era of vectograms, reams of unrecognisable M-mode tracings as well as the first diagnostic cardiac catheterisations in children in South Africa. Angiograms were developed in a dark room and stockpiled to the roof in the Department. These were viewed on a temperamental projector, which only Prof knew how to control.

Prof's clinical skills and auscultatory prowess would often outshine the findings of the ultrasound in the early days. His knowledge, energy and passion for his speciality was unmatched. The registrars used to joke that "what Prof had forgotten, we had yet to learn".

In the early days, interventional cardiac catheterisations, were limited to balloon atrial septostomies and pulmonary valvuloplasties, with unsophisticated equipment. But over time, Prof witnessed and lived through the massive explosion of technology and new equipment in the field of interventional cardiac catheterisations as well as ultrasound/echocardiograms to what they have now become in the current era.

Past registrars will fondly remember his ward rounds and teachings that would go on late into the night. Unfortunately, Prof had no sense of time and ward rounds would only end when he would get an irate phone call from Cynthia telling him that he was late for dinner.

I can clearly remember him coming to do ward rounds on a Sunday morning after playing tennis and walking into the neonatal ICU with his skinny legs protruding from his buttoned up, neatly ironed white coat. He would immediately attract an audience from the doctors on duty who would hover around him in admiration like moths to a flame. He was a true proponent of evidence-based medicine. But his devotion to his patients and caring nature as a clinician revealed his passion for his chosen career. He could remember in detail, most of his patients by name and what their diagnoses were. 
Prof could quote and cross-reference any article in his field long before Medline search engines were even considered. Better still, he would then go and retrieve copies of the original articles from his cluttered office which was filled with publications from the floor to the roof. The walls in his office were plastered with artistic paintings and drawings created by his loving patients. His desk became a storage facility for many more articles and publications when he ran out of shelf space, leaving him to write his reports on his knees. Walking into his office, one could be forgiven for not initially seeing him behind the pile of papers and publications.

Prof's insatiable appetite for knowledge was evident by his huge collection of post-mortem congenital hearts that he kept in the Department of Paediatrics at the Johannesburg Hospital. His collection of 300 - 400 hearts could match any collection worldwide. Each heart was meticulously categorised and carefully dissected with his dissection kit that he had kept from when he was a second-year medical student in 1946. Often, he would bring out an example of a cardiac condition (usually at 17h00 in the afternoon) and dive in and go through the detailed anatomy and pathology with such eagerness while the students and registrars would back off "crying" from the pungent smell of formalin. These sessions would carry on long after the sun had set. No one would dare leave the teaching session early.

In conjunction with this, he would painstakingly document and photograph all the dysmorphic features in his patients and his slide collection was legendary and filled many drawers in the Department. These photographs made for informative presentations to the Department and at various congresses. His love for photography continued long after his retirement.

Prof was my mentor who taught and guided me and many of my colleagues throughout our training as Paediatric Cardiologists. I was fortunate to have a long-standing close relationship with him starting as a registrar and then as time went by, as a co-consultant at the Johannesburg Hospital and finally as a partner in private practice together with Dr Kenny Govendrageloo. Our private practice was run in the same academic manner to which he had been accustomed for many years.

Standing on Prof's shoulders enabled us to see way into the distance and I will always acknowledge the impact that Prof had on my life, both personally and professionally. I learnt a lot from Prof about cardiology but also about him as a person.

He stood for fairness and equal opportunity for all. He had strong feelings against any form of discrimination and sexism. He showed respect for everybody regardless of their position or standing in society. He was compassionate and he also had the ability to laugh at himself with a great sense of humour.

He was a kind and wonderful husband to Cynthia, a caring and interested father to his 3 accomplished children, Bethia, Trevor and Haidee, as well as a doting grandparent to numerous grandchildren and great-grandchildren, of whom he was so proud. His face would light up and he became so animated when talking about his family.

He was a deeply religious man and actively participated in the activities within the synagogue and was loved, admired and respected by his fellow congregants.

Although Prof Solly's passing leaves a void in many doctors' lives, his legacy lives on within us and we will continue to carry the wonderful memories of him and will cherish the time we had together.

\section{Dr Jeff Harrisberg}

Paediatric Cardiologist, Sunninghill Hospital, Sunninghill, Sandton 